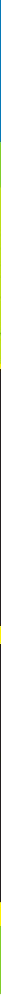

\title{
COMPENDIUM OF BEST PRACTICES IN ROAD ASSET MANAGEMENT
}




\section{COMPENDIUM OF BEST PRACTICES IN ROAD ASSET MANAGEMENT}

January 2018 
(C) 2018 Asian Development Bank

6 ADB Avenue, Mandaluyong City, 1550 Metro Manila, Philippines

Tel +632632 4444; Fax +6326362444

www.adb.org

Some rights reserved. Published in 2018.

ISBN 978-92-9261-068-5 (Print), 978-92-9261-069-2 (electronic)

Publication Stock No. TCS179047-2

DOI: http://dx.doi.org/10.22617/TCS179047-2

The views expressed in this publication are those of the authors and do not necessarily reflect the views and policies of the Asian Development Bank (ADB) or its Board of Governors or the governments they represent.

$\mathrm{ADB}$ does not guarantee the accuracy of the data included in this publication and accepts no responsibility for any consequence of their use. The mention of specific companies or products of manufacturers does not imply that they are endorsed or recommended by ADB in preference to others of a similar nature that are not mentioned.

By making any designation of or reference to a particular territory or geographic area, or by using the term "country" in this document, $\mathrm{ADB}$ does not intend to make any judgments as to the legal or other status of any territory or area.

This work is available under the Creative Commons Attribution 3.0 IGO license (CC BY 3.0 IGO)

https://creativecommons.org/licenses/by/3.0/igo/. By using the content of this publication, you agree to be bound by the terms of this license. For attribution, translations, adaptations, and permissions, please read the provisions and terms of use at https://www.adb.org/terms-use\#openaccess

This CC license does not apply to non-ADB copyright materials in this publication. If the material is attributed to another source, please contact the copyright owner or publisher of that source for permission to reproduce it. $\mathrm{ADB}$ cannot be held liable for any claims that arise as a result of your use of the material.

Please contact pubsmarketing@adb.org if you have questions or comments with respect to content, or if you wish to obtain copyright permission for your intended use that does not fall within these terms, or for permission to use the ADB logo.

Notes:

In this publication, “\$” refers to US dollars.

ADB recognizes "China" as the People's Republic of China.

Corrigenda to ADB publications may be found at http://www.adb.org/publications/corrigenda 


\section{Contents}

Figures and Table $\quad$ iv

Acknowledgments $\quad$ v

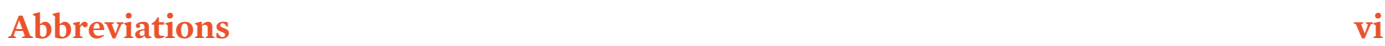

Introduction 1

What Is Road Asset Management? 2

Road Asset Management Systems in the Central Asia Regional Economic

Best Practices 7

1. Limit the Data to be Collected 8

2. Make the Database Easy to Use 10

3. Start with Simple Software 12

4. Institutionalize from the Start 14

5. Publish Annual Performance Statistics 16

$\begin{array}{ll}\text { 6. Integrate into Decision-Making Processes } & 18\end{array}$

7. Provide Sufficient and Predictable Funding 20

8. Separate Management from Implementation 22

9. Ensure High-Level Support 24

10. Continue Development Support 26

11. Develop the Works Implementation Capacity 28

$\begin{array}{lr}\text { Country Status Reports } & 30\end{array}$

Afghanistan 31

Azerbaijan $\quad 32$

People's Republic of China

Georgia 34

Kazakhstan $\quad 35$

Kyrgyz Republic $\quad 36$

$\begin{array}{ll}\text { Mongolia } & 37\end{array}$

$\begin{array}{ll}\text { Pakistan } & 38\end{array}$

$\begin{array}{ll}\text { Tajikistan } & 39\end{array}$

$\begin{array}{lr}\text { Turkmenistan } & 40\end{array}$

Uzbekistan $\quad 41$ 


\section{Figures and Table}

Figures

1 Road Asset Management and Road Asset Management System

4

2 Pavement Quality Index in Yunnan Province, People's Republic of China

17

3 Road Network Condition under Different Budget Scenarios in the People's Republic of China

Table

Central Asia Regional Economic Cooperation Country Progress

in Road Asset Management 


\section{Acknowledgments}

This Compendium of Best Practices in Road Asset Management was developed as part of the support of the Central Asia Regional Economic Cooperation (CAREC) Program toward the establishment of competitive transport corridors; the facilitation of movement of people and goods; and the provision of sustainable, safe, and user-friendly transport and trade networks. This compendium was prepared in the context of CAREC's Transport and Trade Facilitation Strategy 2020, and is aimed at improving the management and maintenance of CAREC road corridors through the sharing of good practices that exist within CAREC countries.

Serge Cartier van Dissel, road management consultant for ADB, prepared this compendium. Thanks goes to the different people who contributed information on the experiences with road asset management in the various CAREC countries. Special thanks go to Ko Sakamoto, David Fay, and Debbie Gundaya (consultant) of ADB, for their support in collecting information, and for their contributions to and detailed review of the various versions of this document. Last but certainly not least, the contributions received from the staff of the different road agencies in the CAREC countries must be recognized-those who provided detailed information on the experiences with road asset management in their respective countries, who participated in discussions on the topic of road asset management, and who assisted in the review of this document, correcting and complementing the information where necessary. 


\section{Abbreviations}

$\begin{array}{ll}\text { ADB } & \text { Asian Development Bank } \\ \text { CAREC } & \text { Central Asia Regional Economic Cooperation } \\ \text { COR } & \text { Committee of Roads (Kazakhstan) } \\ \text { CPMS } & \text { China Pavement Management System } \\ \text { dTIMS } & \text { Deighton's Total Infrastructure Management System } \\ \text { GPS } & \text { global positioning system } \\ \text { GUSAD } & \text { maintenance unit (Tajikistan) } \\ \text { HDM4 } & \text { Highway Design and Management (software) } \\ \text { IRI } & \text { International Roughness Index } \\ \text { km } & \text { kilometer } \\ \text { km } & \text { square kilometer } \\ \text { MOT } & \text { Ministry of Transport (PRC, Tajikistan) } \\ \text { MPW } & \text { Ministry of Public Works (Afghanistan) } \\ \text { NHA } & \text { National Highway Authority (Pakistan) } \\ \text { PRC } & \text { People's Republic of China } \\ \text { RAMD } & \text { Road Asset Management Department (Pakistan) } \\ \text { RAMS } & \text { Road Asset Management System } \\ \text { RDMU } & \text { Road Data Management Unit (Azerbaijan) } \\ \text { RMA } & \text { Road Maintenance Account (Pakistan) } \\ \text { RMD } & \text { Road Management Department (Kyrgyz Republic) } \\ \text { RPICD } & \text { Road Policy Implementation and Coordination Department (Mongolia) } \\ \text { RRF } & \text { Republican Road Fund (Uzbekistan) } \\ \text { SCR } & \text { State Committee for Roads (Uzbekistan) } \\ \text { USAID } & \text { United States Agency for International Development }\end{array}$




\section{Introduction}

1. The Central Asia Regional Economic Cooperation (CAREC) Program is a partnership of 11 countries and 6 multilateral development partners. ${ }^{1}$ The aim of CAREC is to promote development through cooperation, leading to accelerated economic growth and poverty reduction. The CAREC Program focuses on regional cooperation in the priority areas of transport, trade facilitation, trade policy, and energy.

2. The CAREC Transport and Trade Facilitation Strategy 2020 was endorsed at the 12 th Ministerial Conference in October 2013. This compendium builds on projects and initiatives undertaken since 1997 to enhance transport and trade, aiming to (i) establish competitive transport corridors; (ii) facilitate the movement of goods and people through CAREC corridors and across borders; and (iii) provide sustainable, safe, and user-friendly transport and trade networks.

3. The Transport and Trade Facilitation Strategy 2020 attaches importance to providing adequate management and maintenance of CAREC road corridors to ensure they deliver the intended level of road service quality.

4. At the 14th Meeting of the CAREC Transport Sector Coordinating Committee in April 2015 (Ulaanbaatar, Mongolia), CAREC member countries reconfirmed the benefits of sharing good practices that already exist within CAREC countries, and endorsed the idea of producing a compendium of best practices in road asset management. ${ }^{2}$

5. This compendium is a first step in collating such good practices across CAREC member countries, and is intended to be updated from time to time. It was produced through a review of openly available information from each CAREC member country.

6. The compendium is mainly intended for the benefit of road agencies responsible for the management and maintenance of CAREC roads.

7. For practicality, the compendium applies a narrow definition of road asset management focused on the Road Asset Management System (RAMS) and its integration into road asset management procedures and practices, as opposed to covering a wider ecosphere of interventions required for road management in general.

1 The CAREC countries are Afghanistan, Azerbaijan, the People's Republic of China (the PRC, represented geographically by Inner Mongolia Autonomous Region and Xinjiang Uygur Autonomous Region), Georgia, Kazakhstan, the Kyrgyz Republic, Mongolia, Pakistan, Tajikistan, Turkmenistan, and Uzbekistan. The six multilateral development partners supporting the CAREC Program are the Asian Development Bank (ADB), the European Bank for Reconstruction and Development, the International Monetary Fund, the Islamic Development Bank, the United Nations Development Programme, and the World Bank.

2 The Summary of Proceedings of the 14th Transport Sector Coordinating Committee Meeting is available at http://www.carecprogram.org/uploads/events/2015/010-TSCC-Meeting-Mongolia/Summary-Proceedings-14thCAREC-TSCC.pdf. 


\section{What Is Road Asset Management?}

Road asset management looks at optimizing the level and the allocation of road maintenance funding in relation to medium- and long-term results on road conditions and road user costs.

8. The objective of road asset management is generally to optimize the economic benefits by minimizing the sum of maintenance costs and road user costs-road asset management looks not only at the maintenance costs for the road entities, but also at the road transport costs for road users, encompassing all the costs related to road transport (total road transport costs). Road asset management can help determine the optimal funding levels that help minimize these total road transport costs for a country, and can demonstrate how available funding can best be allocated to specific roads or road sections, and to specific types of maintenance and repair. In doing so, it does not look at short-term impacts on the road network, but rather at medium- or long-term impacts (generally a time frame of at least 20 years is used).

9. This introduces a significant change from traditional maintenance implementation aimed at repairing as much existing damage as possible within an available yearly budget. Instead, road asset management aims to achieve a specified service level or road condition at the lowest cost. In doing so, it takes a long-term perspective, considering the future impacts of current budget allocations. Such a change in approach often sees a shift from repairing roads in poor condition, to preserving roads in good or fair condition, avoiding them from deteriorating and requiring costly repairs in the future. In the short term, this results in poorcondition roads being given less attention, but, in the long run, frees up funding to address the maintenance backlog.

10. Road asset management is based on an analysis of road data related to inventory, condition, traffic, unit costs, and road deterioration models. The data is entered into a Road Asset Management System (RAMS) that allows the data to be analyzed, and optimal budget levels and allocations to be determined. However, road asset management is more than just the RAMS, and includes the integration of the RAMS into the wider context of structures and procedures within which it operates, complementing the economic optimization criteria of the RAMS with other policy objectives (e.g., connectivity, accessibility, road safety). 
11. A RAMS is considered to include any system that is used to collect, store and process road and bridge inventory, condition, traffic and related data, for road planning and programming purposes. ${ }^{3}$ A RAMS generally involves a computerized road asset management system, encompassing data collection, data management (database), and data analysis.

- Data collection. Involves carrying out surveys and collecting data on the road network. Includes data that continuously changes and needs to be updated regularly (e.g., road condition, traffic) and data that hardly ever changes (e.g., road alignment, topography, surface type).

- Data management. Generally involves a database that brings all the collected data together and makes it readily available for planning and monitoring. May include simple textual or numerical data (e.g., road name, road length), and global positioning system (GPS)-related data (e.g., alignment, road condition) or multimedia files.

- Data analysis. Involves analysis of the collected data to determine the optimal level of required funding and allocation of that funding to different roads and to different types of interventions. Often looks only at pavements, but may also include bridges, other structures, road furniture, and road service stations.

12. However, the RAMS cannot be seen separately from the context it operates in, and the term road asset management will, therefore, have a wider focus, including the integration of the RAMS into the institutional framework, road network planning and programming systems, road sector financing and budget allocation procedures, and implementation of road repair and maintenance. Road asset management looks at the development of appropriate business processes that allow the RAMS to be used effectively to execute the business needs of the entity responsible for the road network.

- Institutional framework. The institutional structure has a significant influence on the role a RAMS may play in the decision-making process. Therefore, it is important to look at the role and position of the RAMS within the existing institutional framework.

- Financing. The impact of a RAMS is dependent on the degree to which it can influence funding levels, and align these with the actual funding needs. Therefore, it is important to look at how the RAMS influences funding levels.

- Planning. A RAMS is only effective to the degree it can influence plans for the road sector and influence the budget allocations to different roads and intervention types. Therefore, it is important to look at the linkage of the RAMS to the existing planning systems.

- Implementation. During implementation, budget allocations are used to carry out planned road interventions. The effectiveness and efficiency of the implementation and, thus, the degree RAMS targets will be met, depends on the capacities of government and private sector contractors and consultants, and the contracting approaches used.

3 Based on definition used in World Bank Transport Note 29: "Success Factors for Road Management Systems." 2006. 
Figure 1: Road Asset Management and Road Asset Management System
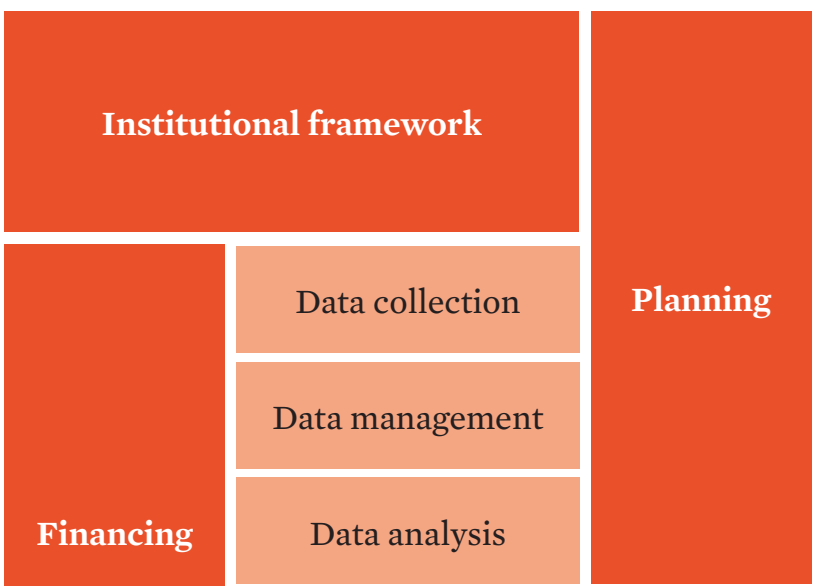

Financing

Data management
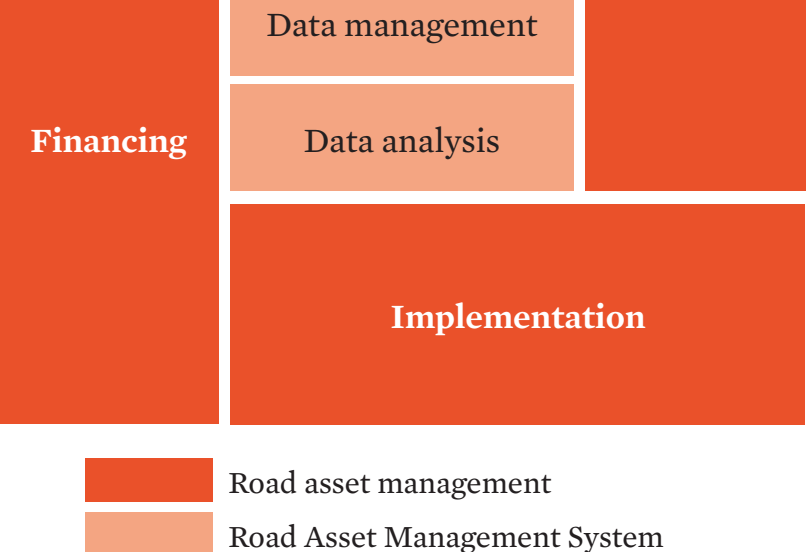

Road asset management

Road Asset Management System

Source: Prepared by ADB consultant. 


\section{Road Asset Management Systems in the Central Asia Regional Economic Cooperation Region}

Six of the eleven countries in the CAREC Program are currently piloting aspects of a RAMS, four other CAREC countries already have a strengthened RAMS in place, and one CAREC country has successfully mainstreamed the RAMS in its road operations.

13. A review of the experiences with road asset management in the 11 CAREC countries was carried out through a desktop review of country and project documents and interviews with a limited number of government staff, development partners, and consultants. This review focused on the trunk road network managed at national level. ${ }^{4}$ A summary of the results is presented below and in the table on the following page. More detailed information for each country is provided in the country status reports in the last section of this compendium.

14. Six CAREC countries (Afghanistan, Kazakhstan, the Kyrgyz Republic, Tajikistan, Turkmenistan, and Uzbekistan) are in the initial phases of developing a RAMS. They are piloting data collection, database development, and data analysis, but this is not yet happening regularly or for only a portion of the trunk road network.

15. Four CAREC countries (Azerbaijan, the People's Republic of China [PRC], Georgia, and Mongolia) can be considered to have a RAMS in place. They regularly collect data in a format suitable for the RAMS, they have proper data management and data quality control procedures in place, and they regularly carry out analysis of the data. However, the RAMS in these countries are still very much a stand-alone tool not yet integrated into decision-making procedures, and mainly used for monitoring.

16. One CAREC country (Pakistan) mainstreamed and integrated the RAMS and is carrying out road asset management. Data collection, management, and analysis is fully institutionalized and carried out regularly. Data analysis forms an input for maintenance planning and influences funding levels and maintenance budgets, and implementation is outsourced in line with maintenance plans. However, it must be noted that this significant achievement is the result of 20 years of support to RAMS development.

4 In the PRC, the trunk road network is managed at provincial level. 
过

일

ind

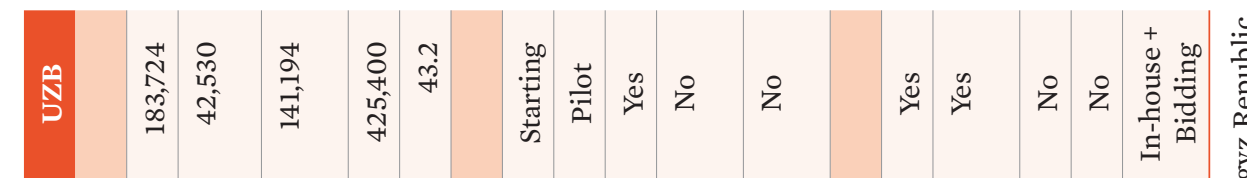

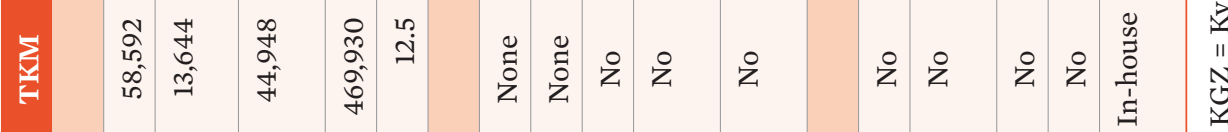

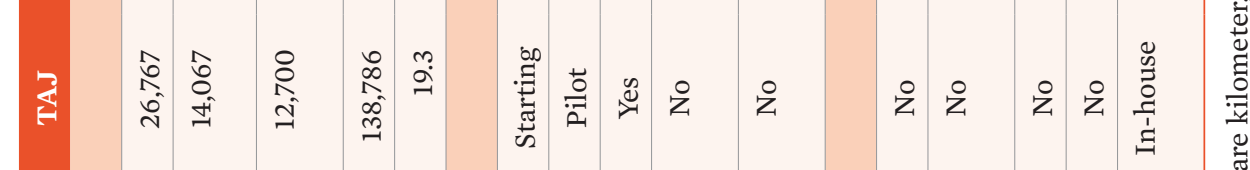

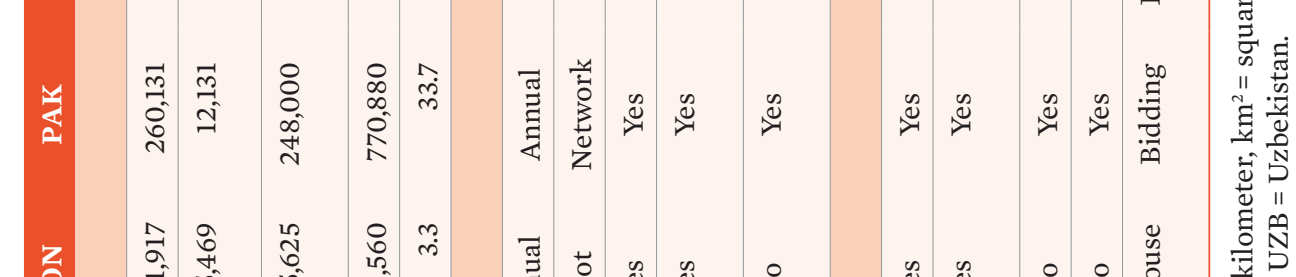

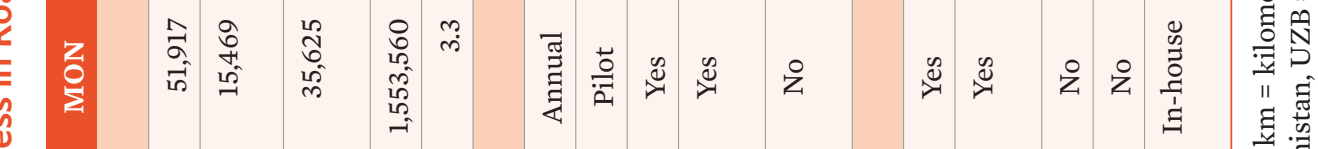

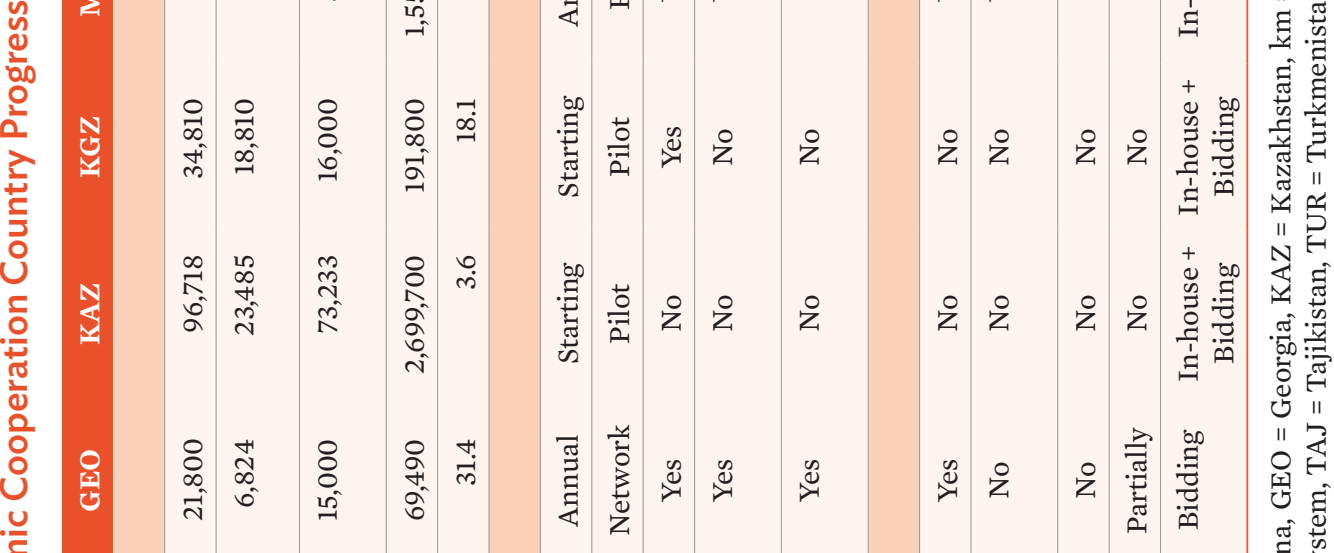

总

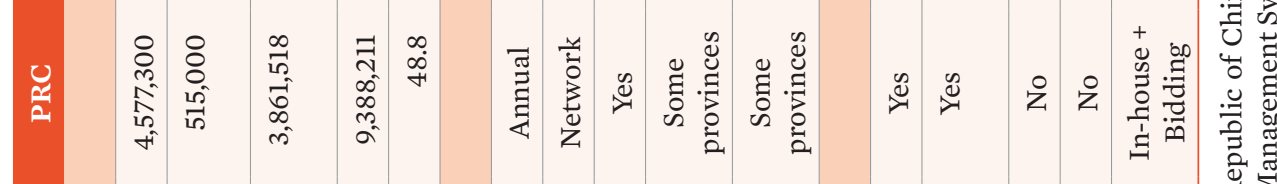

वृ.

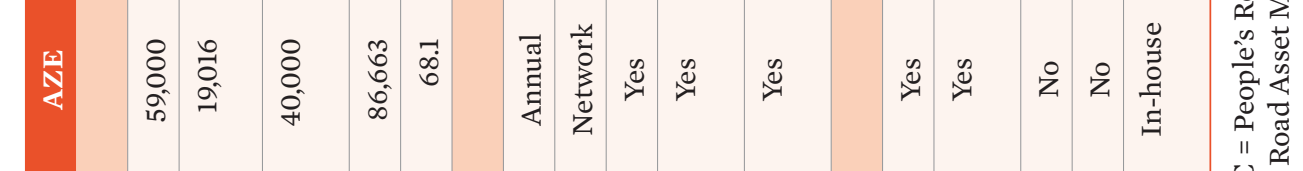

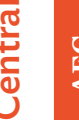

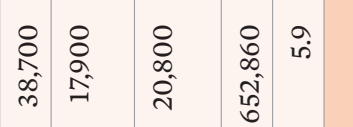

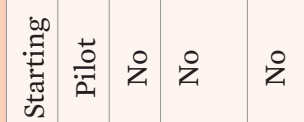

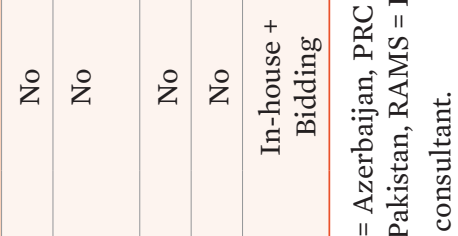

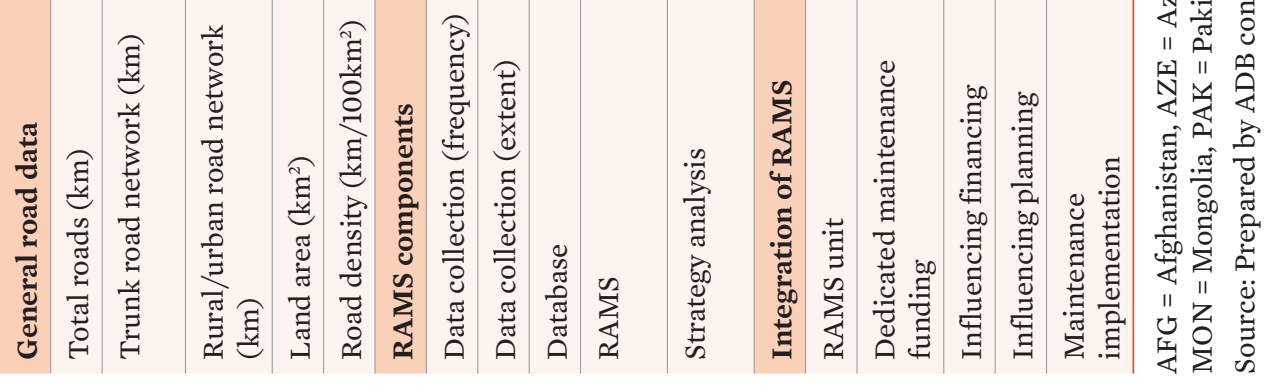




\section{Best Practices}

The following are considered best practices in introducing and developing road asset management:

1. Limit the data to be collected.

2. Make the database easy to use.

3. Start with simple software.

4. Institutionalize from the start.

5. Publish annual performance statistics.

6. Integrate into decision-making processes.

7. Provide sufficient and predictable funding.

8. Separate management from implementation.

9. Ensure high-level support.

10. Continue development support.

11. Develop the works implementation capacity.

17. The review of the current status of road asset management in the 11 CAREC member countries resulted in the identification of common issues the CAREC countries face. These are not necessarily specific to the CAREC region, although the CAREC countries do have some common characteristics, especially since many of the countries were part of the former Soviet Union.

18. The review identified how certain CAREC member countries overcame these issues, providing lessons learned for other member countries. This was complemented by successful experiences from other countries outside the CAREC region and lessons from other studies on road asset management.

19. The result is the identification of a set of 11 best practices considered crucial to the successful introduction of a road asset management system (RAMS), and its integration into the institutional framework, road network planning and programming systems, road sector financing and budget allocation procedures, and the implementation of road maintenance works. These 11 best practices are introduced in detail in the following sections. 


\section{Limit the Data to be Collected}

To limit the time and money spent on data collection, this should focus on minimum data requirements, collected at suitable levels of accuracy, using reliable methods of collection, applying appropriate data formats, and ensuring proper quality control procedures.

20. Road asset management is dependent on data. However, since the collection of data costs time and money, the data collection should be limited to what is actually needed. Collection of data not required or not suitable for use in the RAMS can make data collection too costly, putting the RAMS' sustainability at risk.

21. Many CAREC countries spend time and money collecting data that is not required, too detailed, unreliable, or in a format that is not usable. When designing the data collection, the following requirements should be met:

22. Collect only what is required. A RAMS requires a limited amount of data for the entire network. This should not be confused with the data needs for project preparation, where more detailed data is required, but only for the few roads where interventions are planned. The types of data to be collected for the RAMS should be kept to a minimum, especially for data collected annually. Additional types of data can be gradually added as the RAMS evolves, other data needs are identified, and new data collection methods are introduced.

In Mongolia, annual surveys collected a lot of data that was not used in the RAMS or for other strategic planning purposes. The annual data collection has since been amended to focus on a more limited set of data types that are required for the $R A M S$, reducing the number of data types to be collected from 18 to 2 (roughness and surface condition).

23. Use an appropriate level of accuracy. Although the collection of very accurate data seems like a good idea, this generally increases the cost, while not necessarily improving the outcomes of the RAMS. Especially during the introduction of a RAMS, less expensive data collection methods may be preferable, even where these reduce the accuracy of the data. 
24. Ensure data is reliable. Although a lower level of accuracy is acceptable, the data should be reliable. Only if data is reliable can the level of accuracy be kept within acceptable margins. Unreliable data leads to unreliable results, with errors in the data itself compounding the level of inaccuracy. It is preferable to use proven data collection methods for which there is some experience in the country, ensuring proper calibration and use of equipment. Over time, new technologies can be introduced to improve data reliability or reduce costs.

In the PRC, the introduction of automated survey vehicles greatly reduced the cost of data collection, while at the same time improving data reliability.

25. Ensure data has the correct format. Data must have the correct format to be entered into the RAMS, or should be easily transformed into that format. For instance, qualitative condition measurements of good or bad are not always easily translated into quantitative measurements related to affected surface area.

26. Introduce proper quality control procedures. Before collected data is entered into the database, it should be checked for inconsistencies and processed to fit the database's parameters. This is generally done in a separate database where data is entered and checked before being transferred to the main database.

In Azerbaijan, standards for data quality control and processing were introduced to avoid data errors from being transferred to the database. 


\section{Make the Database Easy to Use}

The database needs to be properly structured, using appropriate software and local language interfaces to make it easily accessible by different levels so it may be used not only for the RAMS, but also for monitoring of road sector performance.

27. Apart from providing a system to manage the data for the RAMS, the road database also performs other functions such as providing data on specific roads and providing statistics on the road network as a whole. It contains a wealth of information for planning interventions and monitoring the road network's performance.

28. To allow the database to provide these functions, it must be made easily accessible. This requires the database to be remotely accessible so that the data can be accessed (and checked) from different offices. This is preferable to sharing several copies of the database, where different copies may contain different data.

29. It also means that the database should be easy to use. This requires an easy webbased interface to search for data, but also a function to export data to commonly used software formats such as Excel or Access, allowing users to further process and analyze the data. Parallel systems may exist for the general public (with a more limited set of data) and for use by authorized government staff (with a more complete set of data).

30. Although not strictly necessary initially, in the long run the system may be further developed to also allow for remote entry of certain data types by local offices. Systems should also allow access to any maps, photographs, and video data included in the database. Moreover, the database should have a local language interface to allow users to easily access data they require.

In the Kyrgyz Republic, Excel was used as the basis for the initial road database. This included the complete road inventory, and road condition data for part of the network. A Russian language interface was developed to facilitate use by the Road Management Department. 
31. Apart from making the database easy to access, the data needs to be well structured. This especially relates to the way that roads are divided into sections, and data is linked to these sections. This requires road sections small enough to accurately pinpoint problem areas, but not too small that the database becomes unwieldly due to the large amounts of data. The location of road sections should also be made easily identifiable, both using maps and GPS coordinates, but also by naming sections according to chainage and/or place names.

In Yunnan Province in the PRC, data is linked to road sections of $1 \mathrm{~km}$ in length, with the chainage of each section recorded in the database. This facilitates analysis by both a RAMS and a simple spreadsheet software.

32. The second element of structuring road sections is the proper use of road codes. Road codes are a series of numbers and letters that uniquely identify each road and, in some cases, even the road section or location. Letters are generally used to identify the type or administrative level of the road, followed by sequential numbering for the different roads of that type. In some cases, additional numbers or letters are included to identify the province, state, or oblast where the specific road section is located. Such a unique identifier is required for all databases, and further assists in identifying the road and its location, avoiding confusion that may exist when road names are used.

In Kazakhstan, road codes exist for the main road network of international roads $(M)$, strategic republican roads $(A)$ and other republican roads $(P)$. However, in existing policies and plans, the road codes are generally omitted and only road names are used, with different documents using different names. This leads to confusion in some cases, where it is not clear which road section is referred to. 


\section{Start with Simple Software}

The introduction of a RAMS should start simple, with inexpensive, easy-to-use software, allowing this to evolve over time as specific needs of the road management entity become clear, and a more detailed RAMS can be developed that responds to these needs.

33. Road Asset Management Systems vary from simple spreadsheets with decision matrices, to complicated software requiring many types of data. In introducing a RAMS, it is important to start simple and gradually evolve to a more comprehensive system that fits the needs of the country and its road network. Several CAREC countries have introduced a RAMS that uses technologies that are costly and difficult to use, undermining its sustainability.

34. During the introduction phase of road asset management, the country will likely be unfamiliar with RAMS and will not be clear on the potential options in data requirements and support to road management. During this stage, a simple off-the-shelf software should be used with the objective of becoming familiar with the possibilities of a RAMS, so it may be subsequently adjusted and upgraded to a country's specific requirements. Too many countries started with complicated software, only to have the system fail due to the high data and skill requirements.

In Belarus, the government started using off-the-shelf Highway Design and Management (HDM4) software as the basis for its RAMS. After several years of implementation, the government decided to develop a specialized system that better responded to its specific needs.

In the Kyrgyz Republic, Microsoft Excel was used as the basis for the first RAMS. This contained the database and could automatically prepare several standardized reports for management purposes. Although simple, it was easily understandable and was made available with a Russian language interface. The World Bank's Road Network Evaluation Tool (RONET) was used to analyze the road data. In the coming years, this will likely be upgraded to other software as the government clarifies what it needs. 
35. Many types of road asset management software are only available in a limited number of languages. This makes them difficult to use in many CAREC countries. To facilitate use of the software, a local language interface should be provided, or an additional front-end module added in the local language. At the very least, a detailed manual that explains the software options in the local language should be provided.

In Mongolia, Deighton's Total Infrastructure Management System (dTIMS) was introduced in 2012 with technical assistance from $A D B$. To facilitate the use of the software, a Mongolian language front-end module was later added. However, due to a lack of qualified professionals, the software is no longer used. 


\section{Institutionalize from the Start}

The RAMS should be institutionalized from the beginning, identifying clear institutional responsibilities and resources for its operation, and involving the RAMS unit in the introduction and development of the RAMS.

36. In many countries, the RAMS was developed with consultant support under the umbrella of a donor-funded road project. The consultant is generally responsible for initial data collection and development of the database and data analysis software, as well as institutionalization of the RAMS and training of staff.

37. However, the focus is often on data collection and system development, with institutionalization and training only happening at the end. This generally gives a less desirable result as institutional structures are not properly designed and tested, and staff members have little opportunity to practice their skills. When the project and consultant support come to an end, the risk is high the system will not work as designed.

38. To avoid this problem, institutionalization needs to be given higher priority and started from the beginning of the RAMS development. No actions should be undertaken until there are clear counterparts to be responsible for data collection, data management, and data analysis. The RAMS unit should have a well-defined structure and sufficient qualified staff assigned to take over the RAMS. The RAMS unit should also have an operational budget assigned to allow it to collect, manage, and analyze the required data.

In Kazakhstan, "instrumental examinations" are expressly mentioned in the budget subprogram 100 of the Committee of Roads. This allows a specific budget to be allocated each year for the collection and management of data.

In Pakistan, a Road Asset Management Directorate was created under the National Highways Authority that is responsible for all data collection, data management, and data analysis. 
39. Only once such a RAMS unit is in place, should the consultant proceed with defining data collection requirements and modalities, data management options, and data analysis procedures. This should take place with full involvement of the staff of the RAMS unit, allowing them to receive on-the-job training and to practice their skills. This will also ensure the RAMS is better adapted to existing data collection procedures and fits better into existing business processes.

In Azerbaijan, a Road Data Management Unit was created under the national road operator, Azeravtoyol, and has been responsible for data collection and management since 2013.

40. To avoid delays in the creation of a RAMS unit, institutionalization should be set in motion during project preparation. Before the project starts, the RAMS unit should be in place, allowing the consultant to immediately start working with the unit's staff. As of the writing of this compendium, RAMS units had been created in only half the CAREC countries, and in some of these countries, the RAMS units were only recently created, or only existed in some provinces.

In Tajikistan, $A D B$ and the World Bank provides continued support for the development of a RAMS. A RAMS unit has not yet been created, but the Economic Analysis and Forecasting Department of the Ministry of Transport has been identified as the possible department for housing the RAMS unit. 


\section{Publish Annual Performance Statistics}

Even where a RAMS is not yet used for decision-making, the publication of statistical yearbooks and performance reports allows the performance of the road sector to be monitored, and provides an incentive for the regular collection of data in support of a RAMS.

41. A RAMS revolves around the analysis of data. However, for this to be possible, the data first needs to be collected and managed. The data collection and management processes need to function well before the RAMS can be successfully introduced.

42. To encourage the annual collection and management of data, even where a RAMS may not yet be fully operational, some countries have started publishing annual performance statistics. These are published in statistical yearbooks or in annual reports. Apart from providing information about the performance of the road sector over time, this ensures the collected data is used. Where such results are made available publicly, these can also introduce greater transparency.

43. The regular collection and publication of such data institutionalizes the concept of data collection and data management, and introduces data analysis as a road management tool. From there, it is a small step to introduce a full-fledged RAMS.

In Georgia, the Road Data Management Unit (RDMU) of the Roads Department is responsible for data collection and for managing the road database. Each year, the Roads Department prepares an Annual Report with support from the RDMU. Increasingly, road data is used for HDM4 analyses in support of planning.

In the PRC, the National Highway Performance Assessment Standards require the different provinces and counties to annually collect data on the road networks under their responsibility. Many provinces use this data only for publication of the Statistical Yearbooks for the road sector in their province, and as input for the national statistical office. However, regular data collection and management means data is readily available for entry into a RAMS as was evident in recent $A D B$ and World Bank projects aimed at strengthening road management. 
Figure 2: Pavement Quality Index in Yunnan Province, People's Republic of China (\%)

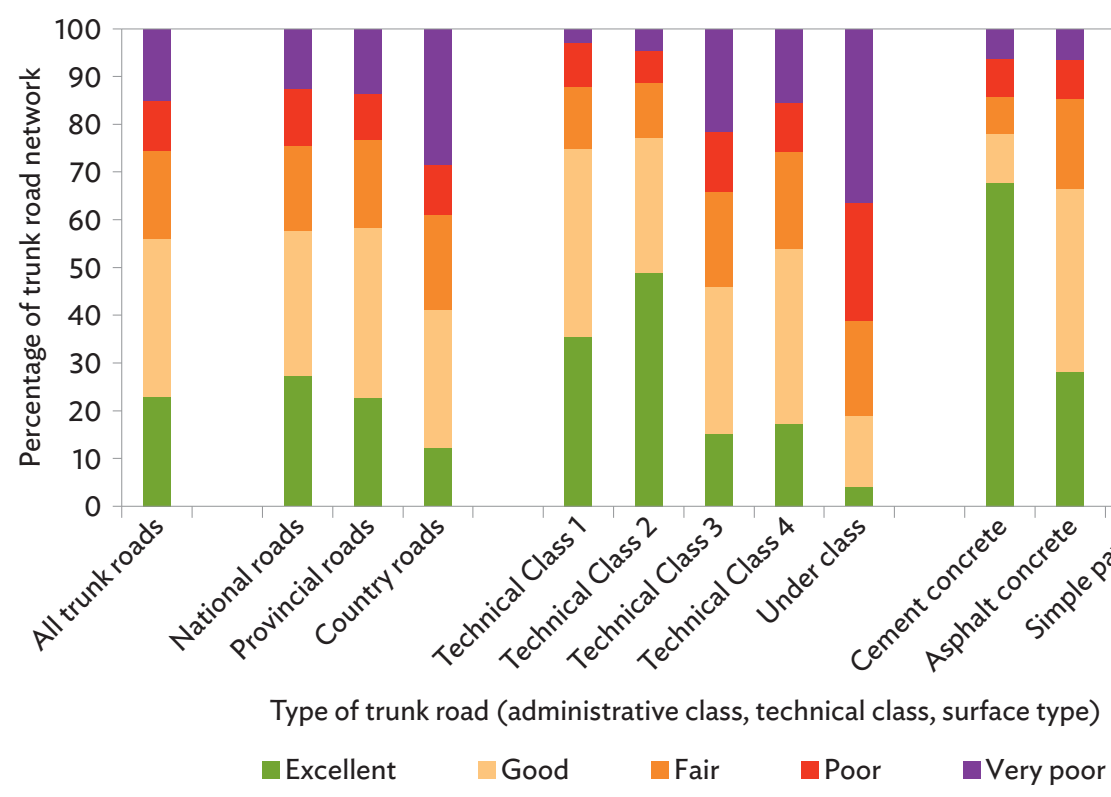

Note: The Pavement Quality Index (PQI) is based on several indicators, the most important relating to surface distress (Pavement Condition Index) and roughness (Riding Quality Index ).

Excellent: $\mathrm{PQI} \geq 90$, Good: 90>PQI $\geq 80$, Fair: 80>PQI $\geq 70$, Poor: 70>PQI $\geq 60$, Very Poor: $\mathrm{PQI}<60$.

Source: ADB. TA 7962, Yunnan Sustainable Road Maintenance Project. 


\section{Integrate into Decision-Making Processes}

The RAMS is ultimately intended as a planning tool rather than a monitoring tool and needs to be integrated into decision-making processes to be effective.

44. A RAMS can be a very powerful tool for determining the optimal use of available maintenance funding in a transparent manner, as well as for determining optimal budget levels for the repair and maintenance of the existing road network. A RAMS can indicate what types of interventions give the best value for money, and can show which roads should be prioritized to get the maximum economic benefit out of the available maintenance budget. In addition, a RAMS can help determine the budget levels required to improve the road network to a minimum condition and keep it there, and indicate what the future effects of different budget levels will be on road network conditions. This makes it a powerful tool for decisionmaking and negotiations on the amount of funding to be allocated to road maintenance.

In Pakistan, road network data is collected annually, entered into the RAMS, and used to prepare annual maintenance plans. The use of the RAMS in the planning and budget allocation process has resulted in a shift toward periodic maintenance, which now receives approximately $60 \%$ of maintenance funding. The results are convincing, with average network roughness reducing from International Roughness Index (IRI) 8.0 in 2000 to IRI 5.6 in 2014. The RAMS is also used to estimate budget needs, which are used in negotiations on the amount of funding to be allocated to the Road Maintenance Account each year.

45. Most CAREC countries have not yet integrated the RAMS into decision-making processes for planning and budgeting and often, the RAMS serves only as a monitoring tool. This is underutilization of the RAMS, which can be a very effective tool in planning and budgeting for road maintenance, repairs, and rehabilitation.

The available maintenance budget in Azerbaijan is estimated to be sufficient to cover existing needs, but a RAMS analysis shows that allocations can be further optimized to preempt a gradual deterioration of the network. 
46. Incorporating the RAMS into decision-making processes requires that the RAMS is properly designed and adapted to fit within existing planning and budgeting procedures. One important aspect to achieve this is to ensure the timing of data collection, management, and analysis fits the country's planning cycle.

47. A more difficult issue is to ensure the output of the RAMS actually feeds into existing planning procedures. Many of the CAREC countries inherited old Soviet Union systems of spring and autumn visual surveys of the road network, with maintenance plans prepared by local-level maintenance units based on perceived needs. A RAMS does not easily fit into this system, where equipment-based survey methods are generally used, data is compiled at central level, and budget is allocated based on the optimization of economic benefits. This will require a transition from local-level planning systems based on visual inspections to more national- or provincial-level planning systems based on data analysis. The draft plans prepared with the RAMS may still be amended based on comments received from local maintenance units or local authorities, as long as these do not divert too much from the economically optimal allocation of maintenance funds.

In Kazakhstan, maintenance is carried out by Kazakhavtodor, which also carries out visual surveys and prepares annual maintenance plans through its local offices. A RAMS is currently being developed that will make use of road condition survey vehicles to collect data. Kazakhstan recently introduced results-based budgeting; linking budgets to the targets to be achieved. This approach fits in well with the RAMS that can help determine appropriate targets based on the available budget, and can also monitor achievement of these targets. 


\section{Provide Sufficient and Predictable Funding}

The investments the RAMS prioritizes are based on predicted medium-term funding levels. These funding levels need to be sufficient and predictable to improve the medium-term road network condition and achieve expected improvements.

48. A RAMS can help determine the amount of funding necessary to achieve a certain road network condition within a given time frame. The RAMS can also show the impact of different funding levels on the road network condition over the medium- and long-term. It is important that this function is used as a basis to determine the level of funding to be provided to the road sector. Without sufficient funding, the RAMS can only optimize the allocation, but it will be unable to ensure an acceptable condition can be achieved for the entire road network. Some CAREC countries already have acceptable funding levels, although the allocation of the available budget needs to be improved, but several CAREC countries need to increase their funding allocations if they wish to gradually improve their road network conditions.

49. Besides providing sufficient funding, of possibly even greater importance is ensuring the level of funding is predictable in the medium term. The RAMS functions on predicted levels of funding for a medium-term period of approximately 20 years, determining how the expected funding may be best allocated to improve the road network condition and reduce transport costs. Where the predicted level of funding is not achieved, the predicted impact will also not be achieved. Especially where funding decreases steeply from 1 year to the next, the benefits of the planned investments can be significantly reduced since interventions are no longer carried out at the moment when these are planned (planned periodic maintenance may be postponed, resulting in a need for rehabilitation in later years).

In the PRC, a fuel tax was introduced in 2009, replacing vehicle maintenance fees, tolls on lower-class roads, and several other user charges. The fuel tax provides a predictable level of funding that increases with road usage.

50. Different countries use different sources of funding to finance the road sector. Internationally, there is a tendency to apply a "user pays" principle, where road user charges are increasingly used to cover the costs of road sector interventions. These include fuel taxes or levies, vehicle registration fees, tolls, etc. These user charges can be based on simple access to the road network (e.g., registration fees), or on the degree of usage (e.g., fuel tax). There is also a tendency to earmark a portion of these road user charges to the road sector to increase the predictability of the funding (a portion of the road sector funding may continue not to be 
earmarked, varying by year). In the CAREC countries, road sector funding continues to be mostly from general budget allocations and is largely not earmarked, increasing the risk of annual variations as political priorities change.

51. Several CAREC countries have introduced Road Funds. These generally receive earmarked funding, often financed from road user charges (although it may also include allocations from general government budgets and development partners). These ensure a steady and predictable flow of funding each year. The Road Fund also manages the funding allocation, ensuring it is based on approved plans and complies with national legislation. Although Road Funds tend to lead to improved road sector financing (in both level and predictability) and budget allocation, such funds are not a strict requirement for a RAMS to function well. It is more important that sufficient funding is provided and funding levels are predictable, which the introduction of a Road Fund does not necessarily ensure.

In Pakistan, a Road Fund was originally envisaged. However, in the end, it was decided to introduce a simple Road Maintenance Account financed from earmarked road user charges, and complemented by government allocations and development partner loans. Despite its more fragile status, it has been very successful, with funding levels being relatively predictable and largely meeting estimated needs. 


\section{Separate Management from Implementation}

A RAMS is a road management tool that can assist the road manager in planning maintenance and repair investments and monitoring performance of maintenance implementation in the road network. It is not intended to support the day-to-day implementation of maintenance works by the implementing entity. Therefore, responsibility for the operation of the RAMS should be assigned to the road manager, separating this function from maintenance implementation.

52. The RAMS is a management tool that helps determine the best allocation of maintenance funding to different types of maintenance and repair, and to different roads or road sections in the network. It focuses on the planning and budgeting phase, comparing possible budget allocations to different types of maintenance and different sections of roads, and selecting the option that leads to the lowest long-term maintenance and road user costs. This is different from the implementation phase, where a more detailed assessment of the specific maintenance needs is prepared only for the selected roads (not for the rest of the network), and the works are carried out.

53. Proper road management requires separation of these responsibilities, with the road manager responsible for planning, budgeting, and performance monitoring, while the implementing entity (contractor) is responsible for achieving the planned results. Where the same entity is responsible for both planning and monitoring the results, and achieving these results, a conflict of interest arises as the entity is responsible for assessing its own performance.

In Afghanistan, a Road Authority is being introduced to manage the road network. With support from the United States Agency for International Development (USAID), a Road Fund is being developed to ensure proper funding for road maintenance. Development partners are also supporting the development of private sector contractors, including the introduction of performance-based contracting.

54. In most of the CAREC countries, the entity responsible for road management is also responsible for implementation by in-house units. These in-house implementation units are also heavily involved in preparing maintenance plans and monitoring road network performance. A minority of CAREC countries moved beyond this and introduced a separation of responsibilities in management and implementation functions. However, in most of these 
countries, the separation is not very clear, causing confusion regarding the placement of the RAMS. There is a tendency to want to place the RAMS with the implementation units as a support tool for works implementation. However, the RAMS is not very suitable for this purpose, and should, instead, be placed with the management unit responsible for mediumto long-term planning, for determining investment allocations, and for defining longer-term financing needs.

In Uzbekistan, Uzavtoyul was responsible for both management and implementation. With the transformation of Uzavtoyul into the State Committee for Roads (SCR), a degree of separation between management and implementation was introduced. SCR is responsible for strategic planning and programming, while the former Uzavtoyul implementation units are set up as unitary enterprises that will be contracted through SCR's Directorate for Construction and Reconstruction of Public Roads.

In Georgia, the Roads Department is responsible for the management of the trunk road network and for the RAMS. The former force account units were privatized in 1999 and all works implementation is currently contracted out to the private sector. This includes routine summer and winter maintenance, which is packaged based on 34 zones and contracted out under 1- or 2-year contracts. Construction supervision is also contracted out, although the Roads Department continues to carry out maintenance supervision. 


\section{Ensure High-Level Support}

To ensure the RAMS is properly integrated into the existing framework and procedures, high-level support is needed and should be mobilized from the start of the RAMS introduction.

55. Although the development of a RAMS is relatively straightforward and can be done largely with project and consultant support, its integration into the institutional framework and decision-making procedures requires support from high-level officials. Without such high-level support, the RAMS will continue to be a stand-alone tool, with little impact on road management.

56. To achieve such support, it is important to convince high-level officials of the RAMS' benefits as a decision-making tool, and how it can help determine suitable maintenance budget allocations and optimize the impact of available budgets on road conditions and road user costs. A strategy analysis can be a powerful tool in this process, showing how future road conditions are likely to evolve under different budget scenarios, and demonstrating how available budgets are best allocated to different types of roads and maintenance, comparing these to current practices.

In Yunnan Province in the PRC, a strategy analysis was carried out in 2011 (Figure 3). Three budget scenarios were analyzed, including the existing budget and two budgets with increased allocations from the fuel tax. The results show how an optimized allocation of the existing road maintenance budget leads to improved road conditions for roads with higher traffic volumes, and how an increase in maintenance funding is needed to achieve a gradual improvement of conditions for all trunk roads. The RAMS results show a shift in focus in the allocation of the available budget from rehabilitation of roads in poor condition to periodic maintenance of roads with high traffic volumes in good or fair condition. Additional budget allocations are used to expand periodic maintenance and rehabilitation to roads with lower traffic volumes. 
Figure 3: Road Network Condition under Different Budget Scenarios in the People's Republic of China
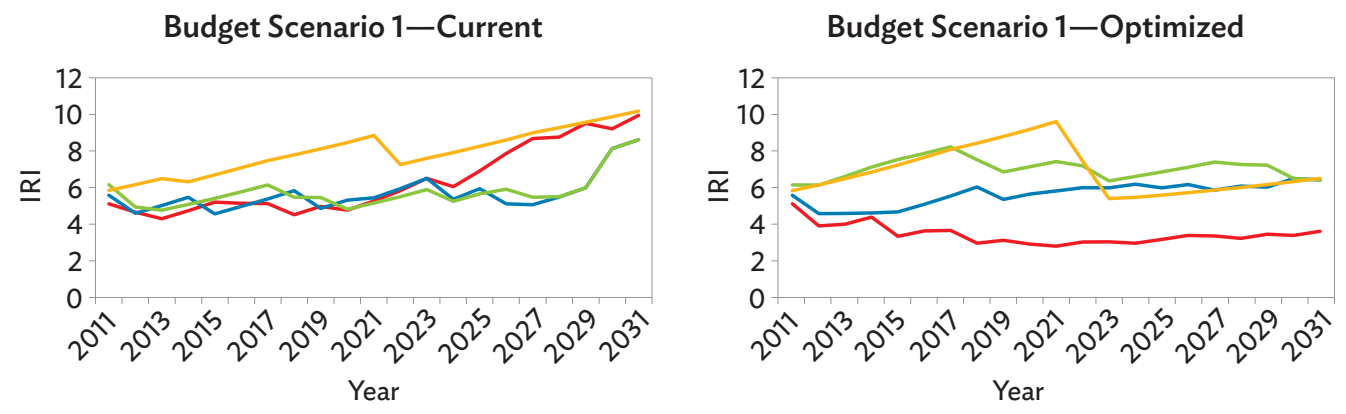

Budget Scenario 2-Optimized
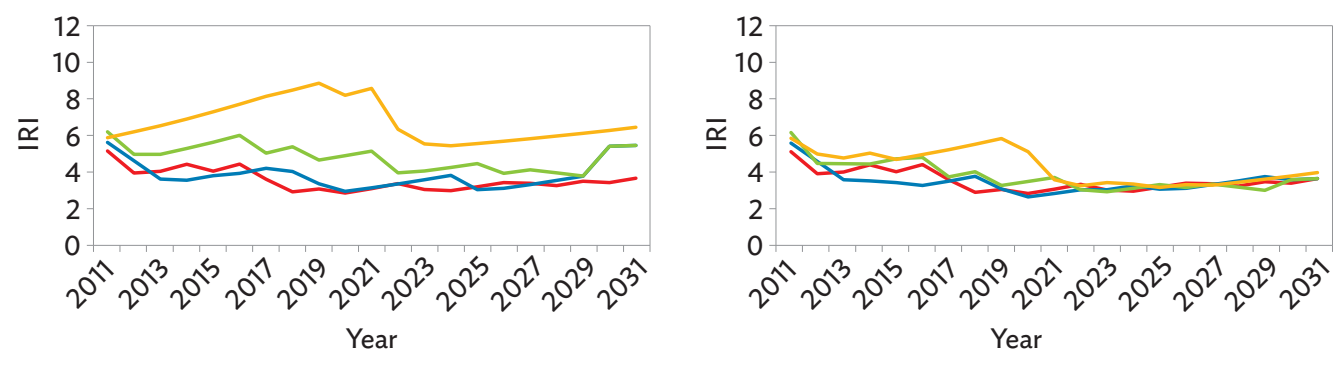

$-\mathrm{T} 1-\mathrm{T} 2-\mathrm{T} 3-\mathrm{T} 4$

$\mathrm{T} 1 \leq 1000 \mathrm{ADT}, 1000 \mathrm{ADT}<\mathrm{T} 2 \leq 2000 \mathrm{ADT}, 2000 \mathrm{ADT}<\mathrm{T} 3 \leq 4000 \mathrm{ADT}, \mathrm{T} 4>4000 \mathrm{ADT}$, ADT $=$ average daily traffic, IRI = International Roughness Index.

Source: ADB. TA 7962, Yunnan Sustainable Road Maintenance Project.

In the PRC, the Ministry of Transport strongly promotes the use of its China Pavement Management System (CPMS) for maintenance planning. However, the high degree of decentralization and the large number of entities responsible for the trunk road network, make implementation difficult, despite the high-level support.

57. Such high-level support is not strictly necessary at the beginning, but should be mobilized as soon as possible to ensure the RAMS is integrated into existing procedures. The high-level support does not necessarily have to come from the road sector, and may come from a finance ministry or planning ministry.

In Kazakhstan, the Ministry of Finance introduced results-based budgeting. This requires annual targets to be set for key performance indicators in each sector. This approach is in line with a RAMS and will support the introduction of a RAMS in the road sector. 


\section{Continue Development Support}

The introduction and development of a RAMS and its successful integration into decisionmaking procedures takes at least 5-10 years. Technical support needs to be provided throughout this period.

58. Development partners strongly support the RAMS introduction in the CAREC countries. This is generally done on a project basis, with project consultants providing technical assistance and project funding used to procure survey equipment, and hardware and software for the database and data analysis modules.

59. CAREC countries and development partners are learning how the RAMS introduction can be better supported. One common challenge is the time frame for a single project. This is often too short to allow for full development and integration of a RAMS, that usually takes 5-10 years, and often even longer. Projects tend to not look beyond the end of the project period and, during project design, little attention is given to follow-up support after the end of the project. Achieving RAMS piloting, strengthening, and mainstreaming in a single project has been found to be overly ambitious.

In Pakistan, the introduction of the RAMS for national highways and motorways already started in the 1990s. It has sustained its efforts over the past 20 years to get to the current stage, and some provinces are currently embarking on this process.

60. With different development partners involved in supporting the introduction of a RAMS, proper coordination is required to ensure the different projects complement each other. To ensure a coordinated and continuous support to RAMS development, stepwise support through a series of consecutive projects is required. The consecutive steps should be designed beforehand, clarifying what each project will aim to achieve, and how they will build on the previous project's accomplishments. This would require at least three consecutive projects to deal with the following steps: 
1. Piloting the RAMS and awareness raising of its potential (including creating a RAMS unit and mobilizing high-level support)

2. Strengthening the RAMS and capacity development (including expansion of data collection, strengthening of systems, and further training of the staff of the RAMS unit).

3. Mainstreaming the RAMS and integrating it into decision-making (including its use in planning and budgeting, and development of the works implementation capacity)

In Uzbekistan, $A D B$ has been supporting RAMS development for the international and national road networks through two consecutive projects. The World Bank is providing further support by expanding data collection, the database, and the $R A M S$ to the regional road network.

61. Coordination of the different projects and their consecutive stepwise support should be led by the government, and strongly supported by development partners and project (preparation) consultants. As the RAMS develops, it may be expanded to include other parts of the network.

In Georgia, the World Bank has been supporting the introduction of road asset management for more than 10 years through a series of several different projects. Where the focus was initially on international roads, this was subsequently expanded to include secondary roads and even local roads, with a detailed road inventory carried out in support of the RAMS. The functions of the RAMS are also continuously improved and expanded in each subsequent project, with improvements in data collection equipment, updates to database and RAMS software, and additions of new functions, such as a bridge management system and a road safety management system. This stepwise approach appears to be leading to the government's successful adoption of the RAMS. 


\section{Develop the Works Implementation Capacity}

The use of a RAMS tends to result in a shift in the types of maintenance and repair carried out, with greater attention given to preventive periodic maintenance of roads in good or fair condition. This requires the development of suitable technologies and capacities in the contracting industry, including the availability of suitable equipment to ensure quality and efficiency.

62. Many of the CAREC countries are currently focusing on routine maintenance complemented by rehabilitation of roads in very poor condition. A lack of funding for rehabilitation means routine maintenance is carried out even on roads in poor condition. This results in excessive expenditure on patching, where periodic maintenance is likely to be more efficient. Periodic maintenance is also likely to be more effective in such roads, improving the overall state of the pavement and reducing roughness. A RAMS analysis can clearly show the impact, on both medium- to long-term maintenance costs, but especially on road conditions and road user costs.

63. A RAMS analysis generally recommends more periodic maintenance, especially for roads in fair condition. This is at the cost of roads in poor and very poor condition, especially where these carry little traffic. The idea is that timely periodic maintenance of roads in fair condition will reduce the need for investment in routine patching, and will avoid the need for costly rehabilitation in the future, freeing up funding to finance backlog maintenance.

In Mongolia, a recent RAMS analysis identified the urgent need for periodic maintenance of the main national roads linking to the PRC and the Russian Federation, as well as a large portion of the rest of the national road network. However, in the past, the focus was on carrying out routine maintenance and rehabilitation, and little experience exists in implementing periodic maintenance. Therefore, further support is needed to develop adequate skills and capacities, and to ensure sufficient financing to implement this ambitious periodic maintenance program. 
64. The application of high quality surface treatments, chip seals, overlays, etc., can greatly extend a road's life. However, to achieve the desired quality and benefits of periodic maintenance, suitable equipment and contractors experienced in applying the periodic maintenance treatments are required. Existing equipment and skills in many CAREC countries are focused on routine patching and larger rehabilitation works, and little experience exists in periodic maintenance.

In Pakistan, the National Highway Authority is responsible for management of the trunk road network. It has a Road Asset Management Directorate for planning and budgeting maintenance works and monitoring performance. Implementation of maintenance works is contracted out to private sector contractors on a competitive basis. In 2014-2015, periodic maintenance made up 59\% of the total maintenance expenditure for roads managed by NHA. Several years of carrying out periodic maintenance resulted in many contractors with suitable experience and appropriate equipment.

65. Where suitable implementation capacity does not yet exist, this can be developed through training and support to contractors. Especially in a competition-based context, contractors are generally quick to develop the desired capacities to have an advantage over their competitors. In the case of in-house units, it generally takes longer to introduce such changes as there is no commercial incentive for change and improvement.

66. Traditional contracting arrangements with volume-based payments do not provide proper incentives for implementing maintenance in a timely manner (when volumes are small). The introduction of alternative arrangements, such as performance-based contracting, often with multiannual contracts, can lead to better results at a lower cost. Such contracts also link up well with a RAMS, with both focusing on performance. The RAMS data can also be used to monitor contractor performance. 


\section{Country Status Reports}

Six of the eleven CAREC countries currently pilot aspects of a RAMS, four CAREC countries have a strengthened RAMS in place, and one CAREC country successfully mainstreamed and integrated the RAMS.

67. The following pages provide an overview of the status of the different CAREC countries regarding road asset management. The countries can be roughly divided into three groups.

68. The first group includes countries where the RAMS has been introduced and is being piloted with support from development partners. This is the first stage of RAMS development. Some road data collection has been carried out, a database has been developed, and some data analysis has been done, although, in some cases, only for project purposes. However, the systems are only pilot versions, often implemented by project consultants, and are not yet sustainable. Afghanistan, Kazakhstan, the Kyrgyz Republic, Tajikistan, Turkmenistan, and Uzbekistan are in this group.

69. The second group of countries managed to strengthen the existing RAMS, and are in the second stage of RAMS development. Data collection takes place for most of the trunk road network and is repeated in consecutive years, the database has been further developed, and data analysis takes place for the entire trunk road network, going beyond the project scope. Generally, responsibility for the RAMS has been institutionalized to a degree, with a RAMS unit in place. However, the RAMS' results do not influence annual maintenance planning and budgeting yet. Azerbaijan, the PRC, Georgia, and Mongolia are in this group.

70. The last group includes countries where road asset management has been mainstreamed, and which are in the final stage of RAMS development. Road data collection, management, and analysis are carried out regularly, and are institutionalized. The RAMS results are used in preparation of annual and multiannual maintenance plans, and in preparation and negotiation of budget requests. A strong and competitive implementation capacity exists to carry out the different maintenance types in line with plans. Currently, only Pakistan is in this group, although other countries are likely to join in the near future. 


\section{Afghanistan}

$\begin{array}{lrlr}\text { Land area: } & 652,860 \mathrm{~km}^{2} & \text { Trunk road network: } & 17,900 \mathrm{~km} \\ \text { Road network: } & 38,700 \mathrm{~km} & \text { Road density: } & 5.9 \mathrm{~km} / 100 \mathrm{~km}^{2}\end{array}$

71. Afghanistan has a low road density. The Ministry of Public Works (MPW) is responsible for regional and national highways, and provincial roads. It has provincial offices and carries out most work through in-house units.

72. Data collection was carried out in the past with support from USAID and Japan International Cooperation Agency, although this focused on project investments rather than full network surveys. The Transport Sector Master Plan, including a nationwide road inventory, was updated in 2017 with ADB support.

73. A Road Maintenance Unit was created under MPW with project funding, and HDM4 was used for data analysis. However, this was oriented toward project investments. The RAMS was not institutionalized, and the Road Maintenance Unit was dissolved at the end of the project. More recently, with support from USAID and ADB, the concept of a Road Authority was introduced, with responsibility for management of the trunk road network. Although the Road Authority has yet to be established, it could be a suitable candidate to house a RAMS unit.

74. Road sector financing is very dependent on donor funds, with government only providing a small portion of the estimated maintenance funding needs. USAID and ADB are supporting the creation of a Road Fund with sustainable financing based on user charges, but this has not been established yet.

75. Although most works are carried out through force account by MPW in-house units, several projects have involved contractors in maintenance, especially through performancebased contracts. Security issues are a concern, hampering data collection, implementation, and supervision. 


\section{Azerbaijan}

$\begin{array}{lrlr}\text { Land area: } & 86,663 \mathrm{~km}^{2} & \text { Trunk road network: } & 19,016 \mathrm{~km} \\ \text { Road network: } & 59,000 \mathrm{~km} & \text { Road density: } & 68.1 \mathrm{~km} / 100 \mathrm{~km}^{2}\end{array}$

76. Azerbaijan has the highest road density of the CAREC countries. The trunk road network is managed by Azeravtoyol, a semiautonomous state-owned company responsible for construction, rehabilitation and maintenance. Almost all maintenance works are carried out by in-house district maintenance units under Azeravtoyol. Some performance-based contracts have been piloted with private contractors.

77. With support from the World Bank, a full inventory of the state roads was carried out in 2012. Identification of the roads belonging to Azeravtoyol was a challenge. Data collection included GPS, geometric, and roughness data, as well as video logging. Specific survey equipment was procured for this purpose. Azeravtoyol continued data collection in the subsequent years.

78. A Road Network Databank was developed in 2012, after a previous database was never fully operational. Standards for quality control and data processing, including external auditing, were developed to improve reliability of the data. The database allows for direct transfer of data to HDM4.

79. A Road Data Management Unit (RDMU) was created in Azeravtoyol responsible for data collection, management, and analysis. Staff members were trained and involved in data collection under the World Bank projects. HDM4 is used for analysis, and RDMU staff members prepare annual reports on HDM4 results and network status.

80. Maintenance is funded from the Road Fund that was restored in 2007, and is funded from several earmarked road user charges. Maintenance planning is still done based on needs identified by the district maintenance units under Azeravtoyol. HDM4 analysis shows the amount of maintenance funding is in line with needs, but allocation needs to be improved, giving higher priority to periodic maintenance and to roads in good-fair condition. 


\section{People's Republic of China}

$\begin{array}{lllr}\text { Land area: } & 9,388,211 \mathrm{~km}^{2} & \text { Trunk road network: } & 515,000 \mathrm{~km} \\ \text { Road network: } & 4,577,300 \mathrm{~km} & \text { Road density: } & 48.8 \mathrm{~km} / 100 \mathrm{~km}^{2}\end{array}$

81. The PRC is the largest of the CAREC countries and has by far the largest road network, and the second highest road density. The Ministry of Transport (MOT) decentralized responsibility for the trunk road network to the 27 provincial departments of transport and the transport bureaus in the four major cities. In some provinces, responsibility was further decentralized to prefecture (city) level. Public or private companies often manage expressways. In many provinces, in-house units still carry out maintenance. Performancebased contracts with contractors were piloted in several provinces.

82. In 2007, the Highway Performance Assessment Standards introduced a set of road condition indicators, against which local authorities are required to report annually. These standards introduced the need to regularly collect data on the road network, especially regarding pavement defects and roughness. Most provinces purchased automatic survey vehicles, reducing costs, and increasing reliability of data collection. Performance data is published in statistical yearbooks for each province and at national level.

83. Many provinces created specialized units responsible for data collection and management, often as subsidiaries under the highway bureaus. The PRC developed its own RAMS software, the China Pavement Management System (CPMS). Despite the MOT promoting the use of CPMS and support provided by donors, the many entities involved in the road sector has limited its uptake. In most provinces, the CPMS is only used for road monitoring and preparing annual reports, and has yet to be incorporated into budget allocation procedures.

84. Maintenance is mainly funded from a national fuel tax introduced in 2009. Although road sector budgets increased with the introduction of the fuel tax, allocations to road maintenance continue to fall short of estimated needs, especially since a large portion of the fuel tax revenue is used for network development. 


\section{Georgia}

$\begin{array}{lrlr}\text { Land area: } & 69,490 \mathrm{~km}^{2} & \text { Trunk road network: } & 6,824 \mathrm{~km} \\ \text { Road network: } & 21,800 \mathrm{~km} & \text { Road density: } & 31.4 \mathrm{~km} / 100 \mathrm{~km}^{2}\end{array}$

85. International roads and secondary interstate roads are managed by the Roads Department (RD) under the Ministry of Regional Development and Infrastructure (MRDI), while local roads are managed by municipal authorities. International roads tend to be in good condition, but $40 \%$ of secondary roads and $70 \%$ of local roads are in poor condition. All works are contracted out to the private sector that mainly consists of former force account units that were privatized in 1999. Design-build and performance-based contracts have been successfully piloted and are currently replicated in other parts of the network.

86. The World Bank has been supporting development of a RAMS through various successive projects since 2004. Initially, this focused on international roads and was subsequently expanded to also include secondary roads and even local roads. A full inventory of the entire road network was carried out as a basis for the database. Road condition data is currently collected annually for most of the trunk road network, together with traffic and roughness data. The data is entered into a road database linked to Global Information System mapping. The database is managed by the Road Data Management Unit (RDMU) under the RD, created in 2007. The data collection and database are continuously improved and expanded.

87. The RDMU uses the database to prepare the RD's annual report. Recently, the RDMU has been using HDM4 to prepare and annually update 5-year rolling programs for the trunk road sector. The latest World Bank project includes financial disbursements linked to the annual analysis of the road data and preparation of these rolling programs.

88. A Road Fund existed previously, but was abolished in 2004. Road sector funding currently comes from the general government budget, with a significant portion coming from development partners. Funding continues to be aimed mainly at construction. Although the allocations for rehabilitation and periodic maintenance increased significantly over the past 10 years (mainly from development partner funding), routine maintenance continues to be severely underfunded. 


\section{Kazakhstan}

$\begin{array}{lrlr}\text { Land area: } & 2,699,700 \mathrm{~km}^{2} & \text { Trunk road network: } & 23,485 \mathrm{~km} \\ \text { Road network: } & 96,718 \mathrm{~km} & \text { Road density: } & 3.6 \mathrm{~km} / 100 \mathrm{~km}^{2}\end{array}$

89. Owing to its large geographical size, Kazakhstan has a very low road density. The trunk road network falls under the responsibility of the Committee of Roads (COR) under the Ministry of Investment and Development. A road manager, Kazavtozhol, is responsible for dayto-day management of the trunk road network. Routine summer and winter maintenance is carried out by the state enterprise, Kazakhavtodor, while routine, midterm and capital repairs are contracted out. The government planned to introduce performance-based contracting in 2017, but preparation for the first pilot project are currently still underway.

90. Kazakhavtodor currently collects data through spring and autumn surveys. This is based on visual surveys and focuses on surface defects. The data's format and reliability are not yet compatible for use in a RAMS. The World Bank currently supports development of a RAMS, including the procurement and retrofitting of survey equipment. A network inventory is ongoing. It is likely the oblast level road laboratories under the COR will become responsible for data collection, since many of these laboratories already have survey vehicles. Road condition data for a limited length of the main road network was collected in 2017. The road database being developed will be remotely accessible.

91. Discussions are ongoing on responsibilities for data management and data analysis. Possible candidates include the COR, Kazavtozhol, and the research institute, KazdorNII. A National Road Asset Management Center was established, with these stakeholders' participation.

92. Road maintenance funding comes from the Republican Budget, but is insufficient and has decreased in recent years. The government aims to introduce more tolls to fund maintenance of its main road network. The Ministry of Finance recently introduced resultsbased planning and budgeting, where budget allocations are linked to clearly defined targets to be achieved. ADB supported the COR to identify suitable indicators and targets for the road sector, some of which will use the analyzed data from the RAMS. 


\section{Kyrgyz Republic}

$\begin{array}{lrlr}\text { Land area: } & 191,800 \mathrm{~km}^{2} & \text { Trunk road network: } & 18,810 \mathrm{~km} \\ \text { Road network: } & 34,810 \mathrm{~km} & \text { Road density: } & 18.1 \mathrm{~km} / 100 \mathrm{~km}^{2}\end{array}$

93. The trunk road network in the Kyrgyz Republic is managed by the Road Management Department (RMD) under the Ministry of Transport and Communications. There are 5 regional road units (PLUADs), 3 corridor-based road units (UADs) and a State Directorate responsible for most of the maintenance implementation through a total of 57 depots (DEPs) and two state-owned contractors. ADB is currently piloting performance-based maintenance contracts.

94. Although road condition data has been collected in the past, this is not yet done regularly. With recent support from the World Bank, data was collected in a portion of the international road network.

95. An inexpensive Excel database was developed with the full inventory data of the trunk road network. The database also contains all the collected road condition data and can produce standard reports (tables and graphs) for the RMD. It has a Russian language interface to facilitate its use by RMD staff. The World Bank's Road Network Evaluation Tool (RONET) was introduced for analysis of the collected condition data. ADB and the World Bank are currently supporting further development of the RAMS.

96. Maintenance funding comes mainly from the Republican Budget. A Road Fund was enacted in 1998, but revenues go directly to the Republican Budget, from which annual allocations are made to the Ministry of Transport and Communications. Maintenance allocations are very low, forming only one-third of estimated minimum allocations needed to avoid deterioration of the network. The government has been gradually increasing allocations and aims to allocate at least $80 \%$ of minimum needs by 2018 .

97. Budget allocations are based on needs identified by the road units, and are mainly used for capital repair and routine repair and maintenance, with little attention given to periodic repair. 


\section{Mongolia}

$\begin{array}{lrlr}\text { Land area: } & 1,553,560 \mathrm{~km}^{2} & \text { Trunk road network: } & 15,469 \mathrm{~km} \\ \text { Road network: } & 51,917 \mathrm{~km} & \text { Road density: } & 3.3 \mathrm{~km} / 100 \mathrm{~km}^{2}\end{array}$

98. Mongolia has the lowest road density of all the CAREC countries. The trunk road network is managed by the Road Policy Implementation and Coordination Department (RPICD) under the Ministry of Road Transport Development responsible for policy setting and procurement. The Road Transport Development Center, a state-owned enterprise, is responsible for maintenance implementation. Maintenance works are allocated to the 20 state-owned companies (AZZAs) under the RPICD and 8 private companies.

99. $\mathrm{ADB}$ has been supporting the government in the collection of data, providing survey equipment mounted on government vehicles. Survey equipment procured under previous projects fell into disrepair. The project helped reduce the amount of data collected, focusing on data required for planning rather than for design purposes, reducing data needs from 18 to 2 items (roughness and surface condition).

100. Responsibility for data collection was allocated to the Road Research Institute created in 2012. For data analysis, use was made of both HDM4 and dTIMS in the past, although neither had complete data or was being used for maintenance planning. To avoid confusion, it was decided to continue only with the easier-to-use dTIMS. A front-end management module in the Mongolian language was added to facilitate the government's use. However, dTIMS is no longer used due to a lack of qualified personnel. Periodic maintenance plans were prepared using dTIMS. Implementation of the periodic maintenance plans is still awaited.

101. Road maintenance is primarily financed by the Road Fund. Road Fund revenue is limited, covering only $20 \%$ of estimated needs. The lack of additional state budget allocations meant maintenance investments were capped rather than supported by the existence of the Road Fund. However, in 2017, funding was increased under the new Road Law. Maintenance planning is based on the joint inspection by the RPICD, the Road Transport Development Center, and the state-owned companies. 


\section{Pakistan}

$\begin{array}{lrlr}\text { Land area: } & 770,880 \mathrm{~km}^{2} & \text { Trunk road network: } & 12,131 \mathrm{~km} \\ \text { Road network: } & 260,131 \mathrm{~km} & \text { Road density: } & 33.7 \mathrm{~km} / 100 \mathrm{~km}^{2}\end{array}$

102. The National Highway Authority (NHA) manages the trunk road network in Pakistan. All maintenance works are contracted out to private contractors through competitive tendering.

103. The NHA annually collects road network data through a combination of instrumental surveys and visual inspections. The NHA has developed a remotely accessible road database linked to a pavement management system, a bridge management system, a Global Information System, and a contract management system.

104. In the early 1990s a maintenance management system was introduced that, over time, evolved into a RAMS. A Road Asset Management Directorate (RAMD) was created under the NHA in 2000. The RAMD uses HDM4 software for strategy analyses and network programming. The strategy analyses are used in negotiations on budget levels for the trunk road network, while network programming forms the basis for annual maintenance plans.

105. Maintenance is funded from a Road Maintenance Account (RMA) created by ministerial notification. Despite having a more fragile status than a Road Fund, it has been very successful in fulfilling its objectives. The RMA is financed from road user charges, national budget allocations, and loans. The RMA is managed by the RAMD, and its use is limited to maintenance and rehabilitation. RMA's budgets largely meet estimated needs, although recently, provinces have requested roads to be reclassified as national roads, increasing the size and funding needs of the network managed by the NHA. Most of the RMA budget is allocated to periodic maintenance.

106. Certain provincial governments are initiating the use of RAMS for use on the provincial road network. Different development partners support such efforts. The NHA's vast expertise will play an important role in building the capacity of provincial road authorities in this. 


\section{Tajikistan}

$\begin{array}{lrlr}\text { Land area: } & 138,786 \mathrm{~km}^{2} & \text { Trunk road network: } & 14,067 \mathrm{~km} \\ \text { Road network: } & 26,767 \mathrm{~km} & \text { Road density: } & 19.3 \mathrm{~km} / 100 \mathrm{~km}^{2}\end{array}$

107. The Ministry of Transport (MOT) is responsible for Tajikistan's trunk road network. Road maintenance is mainly carried out by 62 maintenance units (GUSADs) under the MOT. However, the MOT is developing a strategy for outsourcing maintenance works, including piloting performance-based contracts.

108. The GUSADs collect yearly inventory, traffic, and visual condition data, although this data is not assembled in a central database, and is not used for monitoring or planning. The World Bank is currently providing support for procurement of survey equipment.

109. A Highway Information System database was developed in the past and is currently being upgraded with support from ADB. The World Bank is providing further support to allow the GUSADs to use the database. ADB and the World Bank are supporting development of a complete RAMS system, likely to be housed in the MOT's Economic Analysis and Forecasting Department.

110. Maintenance funding comes from the state budget and, to a degree, from publicprivate partnerships. A Road Fund existed, but was abolished in 2000. Although road maintenance funding has increased in recent years, it only covers half the estimated maintenance needs. The allocation of existing road user charges to road maintenance could cover most of the needs.

111. The Economic Analysis and Forecasting Department carries out planning, although this focuses on capital works. The State Program on Transport and Development 2010-2025 includes specific budget targets for rehabilitation and maintenance of international and national road networks. The GUSADs prepare annual maintenance plans based on perceived needs. 


\section{Turkmenistan}

$\begin{array}{lrlr}\text { Land area: } & 469,930 \mathrm{~km}^{2} & \text { Trunk road network: } & 13,644 \mathrm{~km} \\ \text { Road network: } & 58,592 \mathrm{~km} & \text { Road density: } & 12.5 \mathrm{~km} / 100 \mathrm{~km}^{2}\end{array}$

112. Turkmenistan's trunk road network is managed by the Turkmenavtoyollary State Concern under the Ministry of Construction. Maintenance works are carried out by in-house road units under Turkmenavtoyollary.

113. Turkmenistan does not currently receive road sector support from development partners. It is understood that RAMS development has not yet commenced, either for data collection or for data management and analysis.

114. Hence, it is recommended to start with a simple road data collection exercise and database, using this for a one-time data analysis exercise to develop a maintenance strategy. This may then form the basis for future project support from development partners. When government shows sufficient interest, such a project may also include continued support to RAMS development. 


\section{Uzbekistan}

$\begin{array}{lrlr}\text { Land area: } & 425,400 \mathrm{~km}^{2} & \text { Trunk road network: } & 42,530 \mathrm{~km} \\ \text { Road network: } & 183,724 \mathrm{~km} & \text { Road density: } & 43.2 \mathrm{~km} / 100 \mathrm{~km}^{2}\end{array}$

115. Until recently, the management of the trunk road network was shared by the Republican Road Fund (RRF) and the joint stock company, Uzavtoyul. In February 2017, Uzavtoyul was transformed into the State Committee for Roads (SCR) and given responsibility for strategic planning and development of policies and programs. Uzavtoyul's implementation units were transformed into unitary enterprises under the SCR, which are contracted through the SCR's Directorate for Construction and Reconstruction of Public Roads.

116. ADB has been supporting RRF and Uzavtoyul in data collection in international and national roads, developing a program for annual surveys and training staff. Bridge condition surveys were simplified, and an attempt was made to also simplify the spring and autumn surveys. However, lengthy government procurement approval procedures hindered provision of road survey equipment. The World Bank is currently expanding data collection to the regional roads that make up the rest of the trunk road network.

117. The existing road database was recently upgraded to link up with HDM4 for data analysis. The new database also corresponds better to the outputs of the spring and autumn surveys, and allows export to an Excel spreadsheet for easy use. The RRF and Uzavtoyul staff members were initially trained to use HDM4, but the lack of a Russian language interface made it difficult to use. Therefore, the Russian language database was expanded to include simple works programming tools, while still allowing exporting to HDM4 for strategy analyses. Although the SCR is now responsible for preparing investment plans, the RRF has to approve these. As such, both the SCR and RRF will benefit from use of a RAMS. A RAMS unit was created under the RRF in the past, but it is unclear what will happen to this under the new structure.

118. RRF funding is estimated to be sufficient to cover maintenance and rehabilitation of the trunk roads, but part of this funding is currently used for development. The percentage allocated to maintenance has been decreasing, with periodic maintenance receiving very limited attention. 


\title{
Compendium of Best Practices in Road Asset Management
}

The objective of road asset management is generally to optimize economic benefits by minimizing maintenance costs and road user costs. This compendium presents the best practices for the introduction and development of road asset management based on a desktop review of the experiences in the 11 member countries of the Central Asia Regional Economic Cooperation (CAREC) Program. These best practices reflect common problems the different CAREC member countries face, and the most successful solutions in the development of road asset management applied by CAREC and non-CAREC countries. This compendium also provides a general introduction to the concept of road asset management and presents an overview of the status of road asset management in each CAREC country.

\section{About the Central Asia Regional Economic Cooperation Program}

The CAREC Program is a practical, project-based, and results-oriented partnership that promotes and facilitates regional cooperation in transport, trade, energy, and other key sectors of mutual interest. CAREC has 11 member countries: Afghanistan, Azerbaijan, the People's Republic of China, Georgia, Kazakhstan, the Kyrgyz Republic, Mongolia, Pakistan, Tajikistan, Turkmenistan, and Uzbekistan. Six multilateral institutions support CAREC's work: the Asian Development Bank (ADB), the European Bank for Reconstruction and Development, the International Monetary Fund, the Islamic Development Bank, the United Nations Development Programme, and the World Bank. ADB serves as the CAREC Secretariat.

\section{About the Asian Development Bank}

ADB's vision is an Asia and Pacific region free of poverty. Its mission is to help its developing member countries reduce poverty and improve the quality of life of their people. Despite the region's many successes, it remains home to a large share of the world's poor. ADB is committed to reducing poverty through inclusive economic growth, environmentally sustainable growth, and regional integration.

Based in Manila, ADB is owned by 67 members, including 48 from the region. Its main instruments for helping its developing member countries are policy dialogue, loans, equity investments, guarantees, grants, and technical assistance.

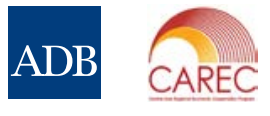

\section{CAREC SECRETARIAT \\ www.carecprogram.org}

\author{
ASIAN DEVELOPMENT BANK \\ 6 ADB Avenue, Mandaluyong City \\ 1550 Metro Manila, Philippines \\ www.adb.org
}

